\title{
TINJAUAN HUKUM ISLAM DALAM PENERAPAN AKAD IJARAH PADA PRODUK RAHN DI CABANG PEGADAIAN SYARIAH ISTIQLAL MANADO
}

\author{
Oleh : \\ Faradila Hasan (faradilahasan6686@gmail.com) \\ Syarifuddin (syarifuddin.mala@gmail) \\ Moh. Muzwir R.Luntajo (muzwir.luntajo@gmail.com)
}

\begin{abstract}
Islamic law doesnot merely regulate the ubudiyah problems, but it also deals with muamalah issues which are closely related to the operational processesof Islamic Financial Institutions (LKS). One of the LKSs is Islamic pawnshops that apply changing ijarah rate on theirRahnproducts in accordance with the loan given to customers despite the equal value of the pawned goods. This practice is not in accordance with the provisions of Sharia fatwaDSN-MUI No. 25 / DSN-MUI / III / 2002 about Rahn.
\end{abstract}

Keywords: Islamic Law, Muamalah,Ijara, Rahn, Shari'a Pawnshops, Fatwa DSN-MUI.

\begin{abstract}
Abstrak
Hukum Islam tidak hanya mengatur mengenai permasalahan ubudiyah saja, melainkan masalah muamalah yang berkaitan erat dengan proses operasional Lembaga Keuangan Syariah (LKS). Salah satu LKS yaitu Pegadaian Syariah, menerapkan produk Rahn yang tarif ijarahnya selalu berubah sesuai dengan pinjaman yang diberikan kepada nasabah walaupun barang yang digadaikan sama nilainya. Maka hal tersebut belum sesuai dengan ketentuan syariah yaitu fatwa DSN-MUI No. 25/DSN-MUI/III/2002 Tentang Rahn.
\end{abstract}

Kata kunci: Hukum Islam, muamalah. ijarah, rahn, pegadaian syariah, fatwa DSN-MUI.

Jurnal Ilmiah Al-Syir'ah Vol. 14 No. 2 Tahun 2016

Institut Agama Islam Negeri (IAIN Manado) 


\section{PENDAHULUAN}

Hukum Islam merupakan unsur yang cukup dominan dalam Islam, berbagai aspek kehidupan hampir tidak ada yang tak tersentuh oleh fikih atau hukum Islam. Dari persoalan ubudiyah hingga muamalah, dari persoalan individu, keluarga hingga negara tidak pernah luput dari sorotan hukum Islam. Bahkan ketika muncul persoalan ditengah-tengan masyarakat, maka yang paling banyak ditanyakan dan paling pertama kali dipersoalkan adalah soal status hukumnya. Bagaimana hukumnya ini, apa hukumnya itu dan seterusnya (Rajafi, 2015).

Terkait dengan persoalan muamalah yaitu mencakup hubungan antarmanusia dengan manusia, maupun manusia dengan badan hukum yang menjadi subjek dari hukum itu sendiri, maka sangat penting diadakannya pembahasan mendalam mengenai hukum bisnis Islam.

Persoalan hukum bisnis Islam dan pengembagannya adalah termasuk salah satu bagian dari pembahasan tentang muamalah, yakni hubungan antarmanusia, baik secara personal maupun kolektif dan dan lebih menjurus pada permasalahan perikatan atau perjanjian. Ini semua merupakan bagian dari kehidupan manusia yang mempunyai dua segi, yaitu segi kebendaan yang dasarnya pertukaran atau pada umumnya memperoleh kebendaan itu dengan perikatan atau perjanjian, dan segi segi kerohanian yang pada dasanya ialah peribadatan, atau dalam bahasa fikihnya adalah ibadah mahda dan gairu mahda. Adapun hukum taklif-nya terangkum pada ahkam al-khamsa, yakni halal, haram, mubah, makruh dan syubhat (Rajafi, 2013).

Hukum bisnis Islam secara khusus mengatur mengenai tata cara pengelolaan keuangan berbasis syariah, dalam hal ini Bank Indonesia (BI) sebagai Bank Sentral berafiliasi dengan Majelis Ulama Indonesia (MUI) untuk mengawasi jalannya lalu lintas keuangan berbasis syariah.

MUI kemudian membentuk Dewan Syariah Nasional (DSN) yang disepakati pada pertemuan tanggal 14 Oktober 1997 dan secara resmi terbentuk pada tahun 1998. Dewan Syariah Nasional mempunyai fungsi antara lain untuk melaksanakan tugas-tugas Majelis 
Ulama Indonesia dalam mendorong dan memajukan ekonomi umat. Di samping itu, lembaga ini bertugas untuk menggali, mengkaji, dan merumuskan nilai-nilai dan prinsip-prinsip hukum Islam (Syariah) untuk dijadikan pedoman dalam kegiatan lembaga keuangan syariah, serta mengawasi pelaksanaan dan implementasinya (Umam, 2012). Kemudian dalam pelaksanaanya LKS di awasi langsung oleh Dewan Pengawas Syariah (DPS).

Secara umum peran dan tanggung jawab Bank Indonesia lebih kepada pengawasan aspek keuangan sedangkan jaminan pemenuhan prinsip syariah adalah tanggung jawab dan kewenangan DSN dengan DPS sebagai perpanjangan tangannya. Dalam hal ini kompetensi dan kemampuan pemahaman syariah tetap wajib dimiliki oleh pengawas Bank dari BI. DPS bertugas mengawasi segala aktivitas bank agar selalu sesuai dengan prinsip-prinsip syariah. Dengan kata lain, DPS bertanggung jawab atas produk dan jasa yang ditawarkan kepada masyarakat agar sesuai dengan prinsip syariah; investasi atau proyek yang ditangani oleh bank harus juga sesuai dengn prinsip syariah, dan tentu saja bank itu sendiri harus di kelola sesuai dengan prinsip syariah (Hidayati, 2008).

Kehadiran Dewan Syariah Nasional (DSN) sebagai lembaga yang menetapkan standar hukum syariah dan mengaudit operasional perbankan syariah di Indonesia dari aspek hukum syariah dapat dianggap sebagai salah satu sarana sosialisasi sekaligus aplikasi dan implementasi hukum Islam di Indonesia dalam bidang muamalah (Hidayah, 2011).

Pegadaian syariah merupakan LKS di Indonesia yang menerapkan produk berbasis syariah salah satu produknya adalah Rahn. Pegadaian syariah melalui produk Rahn menyalurkan dana kepada masyarakat muslim maupun non muslim kelas menengah ke bawah, dalam bentuk pinjaman uang dengan jaminan berupa barang yang berharga.

Produk Rahn itu sendiri dalam penerapanya, menggunakan akad ijarah dan akad rahn. Kedua akad tersebut (ijarah dan rahn) merupakan dua akad yang tidak dapat dipisahkan antara satu dengan lainnya jika kita menggadaikan barang di pegadaian syariah. Fatwa DSN-MUI yang mengatur tentang tata cara pengelolaan produk Rahn yaitu fatwa DSN-MUI Nomor 25 Tahun 2002.

Jurnal Ilmiah Al-Syir'ah Vol. 14 No. 2 Tahun 2016

Institut Agama Islam Negeri (IAIN Manado) 
Secara empiris, penerapan akad ijarah pada pada produk Rahn di Cabang Pegadaian Syariah (CPS) Istiqlal Manado khusus untuk produk rahn emas dari segi penentuan biaya ijarah berubah-ubah sesuai dengan jumlah pinjaman yang diberikan, jika semakin besar atau maksimal jumlah taksiran yang dipinjamkan pada nasabah, maka semakin besar pula nasabah dikenakan tarif ijarah. Begitupun sebaliknya (Bukido dan Hasan, 2016).

Berdasarkan penjelasan di atas, maka artikel penelitian ini akan membahas mengenai tinjauan hukum Islam dalam penerapan akad ijarah pada produk Rahn di Cabang Pegadaian Syariah Istiqlal Manado.

\section{Metode Penelitian}

Penelitian ini bertujuan untuk mengetahui bagaimana tinjauan hukum Islam mengenai penerapan akad ijarah pada produk Rahn di Cabanng Pegadaian Syariah Istiqlal Manado. Penelitian ini dilakukan dengan menggunakan jenis penelitian berdasarkan tujuan yaitu penelitian terapan dan berdasarkan kealamiahan tempat penelitian yaitu penelitian naturalistik oleh Prof. Sugiyono (2014) penelitian naturalistik merupakan nama lain dari penelitian kualitatif. Pendekatan yang digunakan dalam penelitian ini adalah yuridis normatif.

Penelitian memusatkan perhatian pada tinjauan hukum Islam dalam penerapan akad ijarah khusus pada produk Rahn emas. Karena keterbatasan waktu penelitian, penulis hanya dapat mewawancarai 2 orang informan yaitu 2 orang anggota komisi fatwa MUI Provinsi Sulawasi Utara terdiri dari sekretaris komisi fatwa MUI Provinsi Sulawasi Utara dan anggota komisi fatwa MUI Provinsi Sulawasi Utara. Proses wawancara dilakukan pada bulan Juli sampai bulan Agustus 2015.

Pengumpulan data dilakukan melalui proses wawancara dan hasil penelitian mengenai penerapan akad ijarah pada produk Rahn di CPS Istiqlal Manado. Untuk melengkapi data, maka dilakukan juga analisis dokumen yaitu berupa buku-buku serta aturan-aturan yang berkaitan dengan masalah yang diteliti. 


\section{Tinjauan Hukum Islam dalam Penerapan Akad Ijarah pada Produk Rahn Di Cabang Pegadaian Istiqlal Manado}

Penerapan akad ijarah pada produk Rahn di CPS Istiqlal Manado pada penelitian sebelumnya adalah tarif ijarah yang sering berubah-ubah sesuai dengan jumlah pinjaman (Bukido dan Hasan, 2016). Maka menurut penulis hal ini masih belum sesuai dengan ketentuan fatwa DSN-MUI. Untuk itu, penulis selanjutnya pada tanggal 7 Juli sampai 5 Agustus 2015, mewawancarai 2 (dua) orang anggota komisi fatwa MUI Provinsi Sulawasi Utara yaitu Dr. Evra Willya, M.Ag yang merupakan sekretaris komisi fatwa MUI Provinsi Sulawasi Utara dan Dr. Yusno A. Otta, M.Ag sebagai anggota komisi fatwa MUI Provinsi Sulawasi Utara. Untuk mengetahui, apakah menurut MUI penerapan tersebut sudah sesuai atau belum sesuai dengan ketentuan hukum Islam. Wawancara tersebut terdiri dari 8 pertanyaan.

Hasil wawancara kedua anggota Komisi Fatwa MUI Provinsi Sulawesi Utara tersebut, terdapat beberapa perbedaan pendapat diantara keduanya. Yaitu, Ibu Dr. Evra Willya, M.Ag yang cenderung membolehkan penerapan akad ijarah di Cabang Pegadaian Syariah Istiqlal Manado sedangkan Bapak Dr, Yusno. A. Otta, M.Ag yang lebih cenderung berpendapat bahwa penerapan akad ijarah di Cabang Pegadaian Syariah Istiqlal Manado masih belum sesuai dengan ketentuan syariah yang mengacu pada hasil penelitian sebelumnya. Terjadi persamaan pendapat keduanya pada pertanyaan tentang tidak terdapatnya DPS di Cabang Pegadaian Syariah Istiqlal Manado dan merekomendasikan untuk menempatkan DPS di setiap daerah untuk mengawasi produk-produk LKS agar tetap sesuai dengan ketentuan syariah dan fatwa yang ada.

Berikut hasil analisa penulis mengenai tinjauan Hukum Islam dalam penerapan akad ijarah pada produk Rahn di CPS Istiqlal Manado sebagai berikut:

Sebagaimana yang diketahui, pegadaian konvensional beroperasi dengan mendapatkan keuntungan dari bunga atau yang sering disebut dengan sewa modal. Sementara pegadaian syariah mendapatkan keuntungan dari tarif ijarah atau yang sering disebut dengan tarif jasa 
simpan atau tarif ijarah. Pada penerapan produknya pegadaian syariah, mengacu pada Fatwa DSN-MUI diantaranya Fatwa DSN-MUI No. 09/DSN-MUI/IV/2000 tentang Pembiayaan Ijarah, Fatwa DSN-MUI No. 25/DSN-MUI/III/2002 Tentang Rahn dan DSN-MUI No. 26/DSN-MUI/III/2002 Tentang Rahn Emas.

Fatwa-fatwa tersebut menjadi acuan dasar Lembaga Keuangan Syariah (LKS) dalam menerapkan produk-produknya, sehingga pegadaian syariah dapat dikenakan sangsi administratif jika produk yang diterapkan tidak sesuai dengan prinsip syariah (dalam hal ini fatwa DSN-MUI), sebagaimana tercantum dalam Peraturan Bank Indonesia No. 10/17/PBI/2008 dan Surat Edaran Bank Indonesia No. 10/31/DPbS/2008 tentang Produk Bank Syariah dan Unit Usaha Syariah.

Penulis kemudian membandingkan antara teori (fatwa DSN-MUI) dengan penerapan produk akad ijarah Cabang Pegadaian Syariah Istiqlal Manado, hasilnya sebagai berikut:

Pada penerapannya, akad ijarah selalu berdampingan dengan akad rahn, menurut kedua akad tersebut saling berkaitan antara satu dengan yang lain, nasabah tidak bisa menggadaikan barangnya apabila tidak menyetujui salah satu dari akad tersebut di atas. Kedua akad tersbut yang ditandatangani dan disetujui bersamaan oleh nasabah dan pihak CPS Istiqlal Manado. Sehingga, kedua akad tersebut digunakan dalam satu transaksi yaitu pada produk Rahn Emas. Hal ini berkaitan dengan pernyataan dari Bapak Yusno A. Otta yang mengungkapkan bahwa secara substansi, hal itu adalah dua hal yang berbeda. Pertama, tentang akad gadai (rahn) dan yang kedua, tentang akad ijarah (sewa menyewa). Sehingga tidak relevan dengan dengan ketentuan syariah. Maka dari itu, menurut penulis hal tersebut belum sesuai dengan ketentuan syariah, sebagaimana terdapat dalam sebuah hadis yang menyatakan bahwa Rasulullah melarang terjadinya 2 akad dalam satu transaksi.

Selanjutnya, terjadi perbedaan tarif ijarah di CPS Istiqlal Manado apabila barang yang digadaikan sama taksirannya akan tetapi jumlah pinjamannya berbeda. Hal ini telah dicontohkan pada penerapan akad ijarah di hasil penelitian sebelumnya (Bukido dan Hasan, 2016). Jika pinjaman maksimal sesuai dengan taksiran maka tarif ijarah-nya disesuaikan 
dengan yang dipinjamkan begitupun sebaliknya, jika pinjaman di bawah maksimal taksiran maka tarif ijarah pun berkurang, yang oleh pegadaian syariah disebut diskon ijarah.

Menurut hemat penulis, hal tersebut menegaskan bahwa semakin besar jumlah pinjaman maka semakin besar pula tarif ijarah yang dibebankan kepada nasabah. Begitupun sebaliknya, semakin kecil jumlah pinjaman maka semakin kecil pula tarif yang dibebankan kepada nasabah. Seharusnya, besar kecilnya tarif ijarah tidak bisa ditentukan berdasarkan jumlah pinjaman. Karena tarif ijarah hanya ditentukan berdasarkan jumlah taksiran barang, bukan jumlah yang dipinjamkan.

Maka, hal tersebut belum sesuai dengan ketentuan fatwa DSN-MUI Nomor: 25/DSNMUI/III/2002 Tentang Rahn, pada bagian kedua poin 4 yaitu besar biaya pemeliharaan dan penyimpanan marhun tidak boleh ditentukan berdasarkan jumlah pinjaman. Biaya pemeliharaan dan penyimpanan yang dimaksud adalah tarif ijarah. Pada fatwa tersebut menegaskan bahwa tarif ijarah tidak boleh ditentukan berdasarkan jumlah pinjaman.

Secara logika, jika terdapat 2 barang (emas) yang sama nilai taksirannya, disimpan dan dipelihara di tempat yang sama dan dalam kurun waktu yang sama. Mengapa terjadi perbedaan tarif sewa dari tempat tersebut? Sementara jasa yang diterima nasabah adalah sama.

Pada buku saku yang diterbitkan Divisi Litbang Pemasaran Kantor Pusat Perum Pegadaian (2009), karyawan tidak diperkenkan untuk tidak memberitahu adanya diskon tarif atau diskon ijarah kepada nasabah karena tidak diperjanjikan dalam akad. Sementara, tarif ijarah ini merupakan satu-satunya keuntungan (di luar biaya administrasi) yang dapat dihasilkan oleh pihak pegadaian syariah. Yang menjadi pertanyaan mengapa karyawan diarahkan untuk tidak memberitahukan infomasi tentang diskon ijarah. Padahal, informasi tentang diskon ijarah, sangatlah penting untuk diketahui, karena berkaitan dengan biaya sewa tempat yang harus dibayarkan nasabah kepada pihak pegadaian syariah. Pegadaian syariah terkesan berusaha menutupi adanya penerapan diskon ijarah tersebut. 
Beberapa penerapan yang belum sesuai dengan ketentuan syariah atau fatwa DSNMUI diperjelas dengan tidak terdapatnya DPS (Dewan Pengawas Syariah) di Cabang Pegadaian Syariah Istiqlal Manado sehingga tidak ada yang mengawasi operasional Cabang Pegadaian Syariah Istiqlal Manado apakah berjalan sesuai dengan fatwa DSN-MUI atau tidak.

Berikut adalah tugas serta peran dari DPS yang menurut penulis perlu untuk diketaui, yaitu sebagai berikut:

Untuk mengontrol pelaksanaan organisasi dan usaha, agar tetap sesuai dengan prinsip syariah, maka pelaksanaan gadai syariah pada Kantor Cabang Pegadaian Syariah (KCPS) diawasi oleh Dewan Pengawas Syariah (DPS) yang bertindak sebagai patner dari Unit Divisi Syariah PT. Pegadaian (Persero). DPS adalah badan pengawas independen yang ditempatkan oleh Dewan Syariah Nasional (DSN) pada Lembaga Keuangan Syariah (LKS) yang terdiri dari para pakar di bidang syariah, muamalah dan memiliki pengetahuan umum di bidang perbankan dan keuangan. Tugas pokok DPS adalah mengawasi operasional layanan syariah yang berhubungan dengan prinsip-prinsip syariah, sebagaimana yang difatwakan oleh Dewan Syariah Nasional (Ali, 2008). Oleh karena itu, peran DPS itu sendiri, antara lain:

1) Penasihat dan pemberi saran kepada direksi dan pimpinan Divisi Usaha Gadai Syariah mengenai hal-hal yang berkaitan dengan syariah.

2) Sebagai mediator utama Perum Pegadaian dan DSN dalam mengkomunikasikan usul dan saran pengembangan praktik gadai syariah (rahn) yang diawasinya kepada DSN, sekurang-kurangnnya setahun sekali (Ali, 2008).

Peran utama para ulama dalam DPS adalah mengawasi jalannya operasional pegadaian sehari-hari agar selalu sesuai dengan ketentuan-ketentuan syariah. Hal ini karena transaksi-transaksi yang berlaku dalam pegadaian syariah sangat khusus dibandingkan dengan pagadaian konvensional (Rais, 2008).

Dewan pengawas syariah harus membuat pernyataan secara berkala (biasanya setiap tahun) bahwa pegadaian yang diawasinya telah berjalan sesuai dengan ketentuan syariah. 
Pernyataan ini dimuat dalam laporan tahunan pegadaian syariah yang bersangkutan. DPS juga meneliti dan membuat rekomendasi produk baru dari pegadaian yang diawasinya. Dengan demikian, DPS bertindak sebagai penyaring pertama sebelum suatu produk diteliti kembali dan difatwakan oleh DSN (Rais, 2008).

Sebagaimana Surat Keputusan Majelis Ulama Indonesia (MUI) No. Kep98/MUI/III/2001 tentang Susunan Pengurus Dewan Syariah Nasional - Majelis Ulama Indonesia Masa Bakti 2000-2005. Mekanisme Kerja Dewan Pengawas Syariah (DPS) antara lain:

1) Melakukan pengawasan secara periodik pada LKS yang berada di bawah pengawasannya.

2) Berkewajiban mengajukan usul-usul pengembagan LKS kepada pimpinan lembaga yang bersangkutan kepada Dewan Syariah Nasional.

3) Melaporkan perkembangan produk dan operasional LKS yang diawasinya kepada Kepada Dewan Syariah Nasional sekurang-kurangnya 2 kali dalam 1 tahun.

4) Merumuskan permasalahan-permasalahan yang memerlukan pembahasan Dewan Syariah Nasional (Rais, 2008).

Dewan Pengawas syariah yang diharapkan dapat mengawasi setiap LKS yang ternyata tidak terdapat pada CPS Istiqlal Manado, sehingga tidak heran beberapa penerapan produk di CPS Istiqlal Manado belum sesuai dengan ketentuan yang ada. Hal ini diperkuat dengan pendapat dari sekretaris Komisi Fatwa MUI provinsi Sulawesi Utara Dr. Evra Willya, M.Ag yang menngungkapkan bahwa seharusnya, setiap pegadaian syariah di daerah harus mempunyai DPS daerah, karena dengan semakin meluasnya kantor cabang dan agar penerapan prinsip syariah lebih terjamin. Hampir mustahil DPS yang berdomisili di pusat dapat memeriksa dan mengawasi praktek dan kontrak-kontrak yang dilaksanakan oleh pegadaian syariah. Bila hal ini di abaikan, maka pelanggaran prinsip syariah mungkin akan terjadi. 
Hal yang sama juga di kemukakan oleh Dr. Yusno A. Otta, M.Ag sebagai anggota komisi fatwa MUI Provinsi Sulawasi Utara yang merekomendasikan dibentuknya perwakilan DPS di daerah untuk tingkat wilayah atau provinsi.

Lebih lanjut Ibu Evra menambahkan bahwa jika tidak terdapat DPS di masing-masing cabang, pegadaian syariah dapat membentuk advisor yang aktif di daerah, atau pegadaian syariah membentuk departemen syariah yang beranggotakan ahli-ahli syariah yang bertugas full-time di bantu oleh staf teknis yang membantu tugas-tugas pengawasan syariah yang telah digariskan oleh ahli syariah tersebut.

Peran DPS sangatlah penting, untuk menjaga atau mengawasi LKS agar menerapkan produk-produknya sesuai dengan ketentuan syariah. Akan tetapi di Cabang Pegadaian Syariah Istiqlal Manado tidak terdapat DPS yang mengawasi. Sehingga produk di Cabang Pegadaian Syariah Istiqlal Manado, masih ada yang belum sesuai dengan ketentuan syariah.

\section{Penutup}

\subsection{Kesimpulan}

Berdasarkan hasil penelitian dan pembahasan yang mengacu pada masalah dan tujuan penelitian, maka dapat disimpulkan bahwa tianjauan hukum Islam dalam penerapan akad ijarah pada produk Rahn di Cabang Pegadaian Syariah Istiqlal Manado masih belum sesuai dengan ketentuan syariah.

\subsection{Saran}

1) Sebaiknya ada DPS (Dewan Pengawas Syariah) disetiap Cabang Pegadaian Syariah.

2) Perlu adanya kajian dari Dewan Fatwa MUI terutama DSN yang berkaitan dengan Diskon Ijarah.

3) Pegadaiaan syariah seharusnya konsisten terhadap penerapan produk yang ada. Jangan membuat kebijakan sendiri sebelum ada fatwa yang menjadi acuan dasar dari penerapan produk di pegadaian syariah. 


\section{Daftar Pustaka}

Ali, Zainuddin. 2008. Hukum Gadai Syariah, Jakarta, Sinar Grafika.

Bukido, Rosdalina dan Hasan, Faradila. 201). Penerapan Akad Ijarah Pada Produk Rahn Di Cabang Pegadaian Syariah Istiqlal Manado. Jurnal Ilmiah Al-Syir'ah, 14(1), 1-19

Divisi Litbang Pemasaran Kantor Pusat Perum Pegadaian. Oktober, 2009. Buku Saku Pengenalan Produk Perum Pegadaian.

Fatwa DSN-MUI No. 09/DSN-MUI/IV/2000 tentang Pembiayaan Ijarah

Fatwa DSN-MUI No. 25/DSN-MUI/III/2002 Tentang Rahn

Fatwa DSN-MUI No. 26/DSN-MUI/III/2002 Tentang Rahn Emas.

Hidayah, Nur. 2011. Fatwa-Fatwa Dewan Syariah Nasional Suatu Kajian atas Aspek Hukum Islam Perbankan Syariah di Indonesia. Jurnal Al-Adalah, 10(1), 13-24.

Hidayati, Maslihati Nur. 2008. Dewan Pengawas Syariah dalam Sistem Hukum Perbankan: Studi Tentang Pengawasan Bank Berlandaskan Pada Prinsip-Prinsip Islam. Lex Jurnalica (Journal of Law), 6(1), 62-76.

Peraturan Bank Indonesia No. 10/17/PBI/2008 tentang Produk Bank Syariah dan Unit Usaha Syariah.

Rais, Sasli. 2008. Pegadaian Syariah: Konsep dan Sistem Operasional (Suatu Kajian Kontemporer. Jakarta: Penerbit Universitas Indonesia.

Rajafi, Ahmad. 2013. Masa Depan Hukum Bisnis Islam di Indonesia: Telaah Kritis Berdasarkan Metode Ijtihad Yusuf Al-Qaradlawi. Cet. 1. Yogyakarta: LKiS. . 2015. Nalar Hukum Keluarga Islam di Indonesia. Cet. 1. Yogyakarta: Istana Publishing

Sugiyono. 2014. Metode Penelitian Kuantitatif Kualitatif dan R\&D. Cet XII. Bandung: Alfabeta.

Surat Edaran Bank Indonesia No. 10/31/DPbS/2008 tentang Produk Bank Syariah dan Unit Usaha Syariah. 
Surat Keputusan Majelis Ulama Indonesia (MUI) No. Kep-98/MUI/III/2001 tentang Susunan Pengurus Dewan Syariah Nasional - Majelis Ulama Indonesia Masa Bakti 2000-2005. Umam, Khotibul. 2012. Legislasi Fikih Ekonomi Perbankan: Sinkronisasi Peran Dewan Syariah Nasional dan Komite Perbankan Syariah. Jurnal Mimbar Hukum Fakultas Hukum Universitas Gadjah Mada, 24(2), 357-375.

Jurnal Ilmiah Al-Syir'ah Vol. 14 No. 2 Tahun 2016 